\title{
La transformación de los espacios de vida y la configuración del paisaje turístico en Puerto Morelos, Quintana Roo, México
}

\author{
Erika Cruz-Coria
}

Universidad de Quintana Roo, Chetumal, Quintana Roo. Email: ecoria84@hotmail.com

\section{Lilia Zizumbo-Villarreal}

Centro de Investigación en Estudios Turísticos UAEMex, Toluca, Estado de México. Email: lzv04@yahoo.com

\section{Neptalí Monterroso Salvatierra}

UAEMex, Toluca, Estado de México. Email: n.monterrososalvatierra@gmail.com

\section{Analuz Quintanilla Montoya}

Centro Universitario de Gestión Ambiental (CEUGEA) de la Universidad de Colima.

Email: analuzqm@ucol.mx

Resumen: La presente investigación aborda el estudio de las transformaciones producidas en el paisaje del poblado de Puerto Morelos, Quintana Roo, por la incorporación de la actividad turística en la vida cotidiana de sus pobladores. A medida que los objetos, usos y el lenguaje del turismo se incorporan a las costumbres, tradiciones, relaciones sociales y estilos de vida de la población; los espacios de vida -laboral, vecinal, doméstico y de ocio- adquieren características físicas poco tradicionales y formas excluyentes de aprovechamiento que contribuyen a configurar y fortalecer paisajes funcionales al capital turístico. La propiedad privada y el mercado de tierras, las políticas para la conservación de los recursos naturales, la deslocalización empresarial, la imagen turística y las oleadas migratorias son factores que han permitido la reorganización de los espacios de vida y, por consiguiente, la configuración de diversos paisajes turísticos a lo largo de la costa.

Palabras clave: Turismo, espacios de vida, transformación, paisajes turísticos, Puerto Morelos.

\section{The transformation of live spaces and the configuration of the touristic landscape in Puerto Morelos, Quintana Roo, México}

Abstract: This research focuses on the study of the transformations in the landscape of the town of Puerto Morelos, Quintana Roo, because of the incorporation of tourism in the daily lives of its inhabitants. As objects, customs 
and language coming from tourism are incorporated into the customs, traditions, social relationships and lifestyles of the population,the live spaces -at work, neighborhood, household and leisure-acquire nontraditional physical characteristics and exclusionary forms of exploitation that help shape and strengthen landscapes functional to touristic capital. Private property and the land market, policies for the conservation of natural resources, corporate relocation, tourism image and migratory waves are factors that have led to the reorganization of the live spaces and allong with that, the setting various landscape resorts along the coast.

Key words: Tourism, live spaces, transformation, touristic landscapes, Puerto Morelos.

\section{A transformação dos espaços de vida e a configuração do paisagem turístico em Puerto Morelos, Quintana Roo, México}

Resumo: Esta pesquisa lida com o estudo das transformações na paisagem da cidade de Puerto Morelos, Quintana Roo pela incorporação da atividade turística no cotidiano de seus habitantes. Como os objetos, usos ea linguagem do turismo são incorporados aos costumes, as tradições, as relações sociais e estilos de vida dos espaços de vida das populações - trabalho, bairro casa e lazer - untraditional assumir características físicas e formas de exclusão de exploração que ajudar a moldar e fortalecer o capital turística funcional paisagens. Propriedade privada e as políticas fundiárias de mercado para a conservação dos recursos naturais, a relocalização corporativa, imagem do turismo e as ondas de migração são fatores que têm permitido a reorganização dos espaços de vida e, portanto, definir diversas paisagens resorts ao longo da costa.

Palavras-chave: turismo, espaços vivos de transformação, paisagens turísticas, Puerto Morelos.

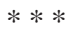

\section{Introducción}

La acelerada modernización, la consolidación de los mercados, la marcada deslocalización de la fuerza de trabajo y, sobre todo, el avance tecnológico han transformado la vida cotidiana en muchos espacios sociales. Si bien, estos cambios han facilitado la vida proporcionando mayor comodidad también han traído consigo nuevas prácticas, hábitos y costumbres que advierten la transformación gradual de la cotidianidad.

Los comportamientos, consumos, gustos, estilos de vida y símbolos de status diferenciados y diferenciantes, diversamente valorizados y cada vez más globalizados se insertan en una dimensión de vida totalmente alienada, característica de nuestra sociedad y del momento cultural que estamos atravesando. La incorporación de «formas culturales modernas» en la vida cotidiana de la población tanto urbana como rural, que se adquieren no sólo a través de los medios de comunicación masiva sino también a partir del desarrollo de diferentes actividades económicas vinculadas al mercado, constituyen una de las expresiones más evidentes del dominio 
cultural capitalista que no es más que la cobertura ideológica sobre la realidad.

Desde esta perspectiva, el presente trabajo de investigación aborda las transformaciones en el paisaje de Puerto Morelos producidas po la incorporación del turismo a la vida cotidiana de este espacio rural. La eventualidad con la que se ha presentado dicha actividad en estos espacios durante las últimas décadas ha creado una atmósfera de presión que invita a sus pobladores a aceptar un modelo cultural que los acerca cada vez más a las formas de consumo y a los estilos de vida del mundo globalizado.

En este sentido, el paisaje social de este poblado es otro, pues a medida que la práctica turística -manifiesta en ciertos objetos, usos y en el lenguaje- se ha venido imponiendo sobre las costumbres, tradiciones, relaciones sociales y estilos de vida de la población, los espacios de vida laboral, vecinal, doméstico y de ocio- también adquirieren características físicas y formas de aprovechamiento que contribuyen a afianzar los paisajes turísticos en la franja costera de este poblado.

En Puerto Morelos, el capital turístico no sólo ha emprendido una dominación económica del espacio -vía la apropiación y valorización ${ }^{1}$-, sino también ha puesto en marcha un proceso de hegemonía ideológica que pude ser visualizada en la vida cotidiana. La forma en cómo la población ha asumido el turismo a través de ciertos objetos, usos y del lenguaje en sus diferentes espacios de vida, responde definitivamente a los intereses de la clase dominante; las instituciones públicas junto con algunas empresas turísticas se han encargado de orientar el actuar de los pobladores transmitiendo ciertas ideas y/o valores en torno al aprovechamiento y conservación de los recursos naturales, al respeto de ciertos espacios que son exclusivos para el turista, a la imagen turística, al consumo, etc., que han restringido y condicionado la manifestación de ciertas costumbres, la continuidad de los estilos de vida antiguos, las relaciones sociales «cara a cara» y, en general, las practicas cotidianas de la población, contribuyendo de esta manera a la configurado de un paisaje que responde a un modelo turístico exclusivo para las clases dominantes.

Dicho lo anterior, se plantean las siguientes preguntas de investigación: ¿Cómo se incorporó el turismo a la vida cotidiana de los pobladores de Puerto Morelos?, ¿el desarrollo de las fuerzas productivas a partir de la implementación del modelo de desarrollo neoliberal permitió la transformación de la vida cotidiana?, ¿la reorganización de los espacios de vida ha contribuido a la configuración de los paisajes turísticos a lo largo de la costa?, ¿qué papel han jugado las instituciones y empresas turísticas en la reorganización de los espacios de vida y en la configuración de los paisajes turísticos?.

La postura teórica en la cual se sustenta la investigación es la corriente crítica, se retoma a Agnes Heller (2002) quien aporta las bases para el análisis de la vida cotidiana a partir del mundo de los objetos, el mundo 
de los usos y el mundo del lenguaje. Por otro lado, se retoma la división de los espacios de vida cotidiana aportada por Alicia Lindón (1997), como una forma de comprender las diferencias culturales de las relaciones con el espacio. El estudio de los espacio de vida cotidiana desde éstas perspectivas permite comprender hasta qué punto los espacios domésticos son espacios regulados, es decir, sujetos a influencias socioeconómicas para configurar algún tipo de paisaje que resulta funcional a ciertos intereses.

En el proceso metodológico la tarea principal consistió identificar aquellos objetos, usos y el lenguaje incorporados por el turismo en los espacios de vida que han dado lugar a una reorganización espacial y paisajística del poblado. Se realizaron entrevistas a pobladores nativos del lugar (pescadores, antiguos chicleros, prestadores de servicios náuticos, taxistas, entre otros), empresarios, pobladores que han migrado de otras partes del país. Las guías de observación, fueron útiles para registrar los usos y restricciones actuales del espacio y, para registrar la serie de símbolos y signos que tanto las instituciones, organizaciones y empresas turísticas utilizan para promover la actividad.

Se encontró que el desarrollo del turismo ha dado lugar a procesos económicos, sociales y políticos específicos como la propiedad privada y el mercado de tierras, las políticas en torno a la conservación de los recursos naturales, la deslocalización empresarial, la imagen turística como parte de la política turística y las oleadas migratorias lo que han permitido la incorporación del turismo en los espacios de vida y, por consiguiente, la configuración de paisajes turísticos a lo largo de la costa.

\section{La incorporación del turismo en la vida cotidiana. Marco teórico de reflexión}

Lo cotidiano es innato a la existencia humana, todo hombre sin importar cual sea el lugar que ocupa en la división social del trabajo tiene una vida cotidiana. Es en ella donde se produce la objetivación de los procesos macrosociales, los cambios que se dan en el modo de producción se expresan en ella a través de las actividades y comportamientos de los hombres (Heller 2002).

Todo sujeto al reproducir su vida participa de la reproducción de un orden existente de manera inconsciente; todo hombre al nacer se encuentra con un mundo ya constituido donde deberá “...aprender a «usar» las cosas, apropiarse de los sistemas de usos y de los sistemas de expectativas” (Heller 2002: 41-42); es decir debe adaptarse a un mundo concreto en el ámbito de un estrato social dado, de ahí que la reproducción del hombre particular sea siempre la reproducción de un hombre histórico. 
La historia como sustancia de la vida cotidiana, no sólo permite conocer los cambios en la cotidianidad misma sino también posibilita comprender las transformaciones en el espacio -y, por consiguiente, en el paisaje- por ser éste el «marco estructural de la vida cotidiana» (Zizumbo 1998). El hombre tiene la capacidad de producir su propio ambiente, consumir ciertos productos y producir otros tantos, manifestar ciertos hábitos y comportamientos también organiza, usa y se desplaza sobre el espacio; por tanto, al transformarse la vida cotidiana también se transforma el marco estructural donde ésta se manifiesta: así como la vida cotidiana es un espejo de la historia, el espacio y el paisaje es un espejo de la propia cotidianidad de los individuos.

De acuerdo con Heller (2002), la vida cotidiana del hombre se encuentra estructurada por tres momentos: el mundo de los objetos, el mundo de los usos y el mundo del lenguaje, mismos que se materializan en el tiempo y el espacio. En el primero, hay que distinguir los objetos en cuanto medios para la satisfacción de las necesidades y los objetos en cuanto a medios de producción; cuando entramos en relación con éstos nos encontramos cada vez más con la naturaleza humanizada, pues cada objeto y cada manipulación de ellos es una prueba de la fuerza del hombre sobre la naturaleza.

En el mundo de los usos encontramos las normas de los usos elementales que tienen como función regular la convivencia social, éstos pueden divergir según las épocas y los estratos sociales pero todos expresan en sustancia el mismo interés social. Dentro los usos elementales se pueden distinguir los usos particulares, los usos condicionados y los usos personales $^{2}$, cabe señalar que para este trabajo sólo se abordaran los dos primeros debido a que éstos tienen que ver con la personalidad del particular, por tanto, consideramos que no son en gran medida el reflejo de los proceso macroeconómicos.

Y finalmente, sí consideramos que toda cultura de determinada época es expresable mediante el lenguaje, entonces, es a través de éste que es posible conocer el mundo de esa determinada cultura pues éste constituye el medio homogéneo de la vida y del pensamiento cotidiano (Heller 1972).

El estudio de la vida cotidiana no está completo si no se toma en cuenta su espacialización. Por lo tanto, sí se parte de la idea de que el espacio es el marco estructural de la cotidianidad, entonces, esta perspectiva brinda la posibilidad de reflexionar acerca de la articulación de los procesos sociales y espaciales a partir de aquellos espacios donde se desenvuelve la vida cotidiana. Para ello, se retoma la propuesta de la división de los espacios de vida aportada por Lindón (1997), la cual comprende cuatro ámbitos: laboral, vecinal, doméstico y de ocio.

En este contexto, habría que preguntarse ¿cómo se incorpora el turismo a estos tres momentos de la vida cotidiana de las poblaciones receptoras?, ¿de qué manera los cambios en la vida cotidiana por el turismo 
contribuyen a la transformación del paisaje local?. El turismo no es una actividad que haya estado siempre presente en la vida cotidiana de los hombres, por el contrario, ésta se ha interiorizando como parte de los cambios macrosociales hasta llegar a creer que su práctica tanto como turista como comunidad receptora es algo "natural".

La actividad turística, bajo la lógica de la acumulación capitalista, es capaz de crear a cada momento relaciones de fuerza de poder y hegemonía que pueden verse reflejadas en la vida cotidiana e incluso pueden sistematizarla proporcionando y regulando ciertos esquemas interpretativos y cognoscitivos que ofrecen un mapa cultural en torno al cual se integran los individuos para lograr la reproducción del orden social establecido por esa lógica dominante.

En el turismo son las instituciones administrativas e incluso las empresas turísticas y hasta los medios de comunicación los que se encargan de la orientación, transmisión y socialización de una concepción del turismo, logrando permear los espacios de trabajo, doméstico/vecinal y los de ocio (Zizumbo 1998, Lindón 1997).

Son estos grupos los que van incorporando a la vida cotidiana ciertos objetos turísticos ${ }^{3}$, al gestionar diversos productos y servicios (infraestructura, transporte, difusión y promoción, hoteles, restaurantes, escuelas de enseñanza del turismo, atractivos turísticos) van organizando y sistematizando la vida cotidiana de la población receptora en torno a esta actividad.

Así el mundo de los usos se va moldeando de acuerdo a la orientación que se le dé al mundo de los objetos, se cristaliza la organización social de la vida cotidiana en torno a ciertos usos elementales, particulares, condicionados y personales que guían también el comportamiento no sólo del turista sino el de la población receptora; así encontramos que se van estableciendo e imponiendo restricciones en torno al uso de los recursos naturales y de ciertos espacios que son destinados al turista, se van marcando pautas bastante claras de consumo, se organiza el espacio a favor de la actividad y el desplazamiento sobre éste, se determina la participación de la población en la prestación de servicios turísticos y, se coartan o condicionan otras tantas actividades, comportamientos y estilos de vida tradicionales que en conjunto contribuyen a la configuración de un paisaje que favorece a ciertos grupos que controlan la actividad.

El contexto en el que se desenvuelve la población receptora también se va enmarcando por el lenguaje; a través de un conjunto de signos, símbolos e incluso como un discurso creado y colectivamente reconocido el lenguaje turístico se va incorporando a los espacios de vida como una forma de interpretación de la realidad. El turismo trae consigo el uso generalizado de nuevos códigos, que supone la producción de un sinfín de bienes culturales que no son sólo una propuesta de consu- 
mo para el turista sino también llega a la población receptora conduciendo sus hábitos y comportamientos así como sus gustos, deseos y apetitos hasta entonces «tranquilamente individualizados» (Yory 2006:86).

De esta forma, el nuevo lenguaje incorporado a la vida cotidiana de las poblaciones receptoras supone, también, el dominio del espacio por parte de los grandes consorcios mundiales quienes -a través de esta nueva economía de signos- están haciendo más fácil la extensa difusión de los modelos de consumo de la cultura dominante.

De acuerdo con Chávez, la actividad turística “... se ha impuesto a la cotidianidad de la comunidad afectando del mismo modo la percepción espacial de su vida y de aspectos culturales tangibles e intangibles” (2009:6). El turismo -a través de sus diferentes actores sociales- se ha venido filtrando en la esfera de lo social, económico, político e incluso se ha impuesto sobre los espacios cotidianos de la población receptora incorporando en ellas nuevos objetos, usos (culturales y del espacio) y un lenguaje que integra a los individuos a un consenso de orden en torno a la actividad turística, produciendo así los sujetos ideológicos buscados para su continuidad y desarrollo.

Desde esta perspectiva, se pretende estudiar la forma en cómo los paisajes de la cotidianidad se han transformado -con evidentes pretensiones homogeneizadoras en lo estético, lo funcional y lo culturalen paisajes del turismo; la incorporación de diversos objetos y prácticas turísticas no sólo han transformado las actividades y comportamientos cotidianos de las poblaciones receptoras sino también el espacio y el paisaje han sido objeto de esa transformación. En nuestro país el modelo de desarrollo turístico ha priorizado la creación de paisajes «plásticos», paisajes perfectos que resultan irreales pues difícilmente se encuentra en ellos la expresión auténtica de la cultura local, de ahí su imposibilidad para fundirse en la cotidianidad del espacio donde se configuran.

\section{Puerto Morelos. Los espacios de vida cotidiana y el paisaje pesquero}

Puerto Morelos es una población costera localizada geográficamente en la zona norte del estado de Quintana Roo, en el municipio de Benito Juárez, limita al norte con la ciudad de Cancún, al sur con la de Playa del Carmen (municipio de Solidaridad) y al este con el poblado de Leona Vicario. En este poblado fue la pesca comercial y, posteriormente, el turismo las actividades económicas a través de las cuales el Gobierno Federal buscó, durante la década de los sesenta, generar las condiciones físicas, humanas y técnicas para la integración de este poblado al desarrollo nacional (Martínez y Camal 2009). 
Figura 1. Ubicación de Puerto Morelos, Quintana Roo.

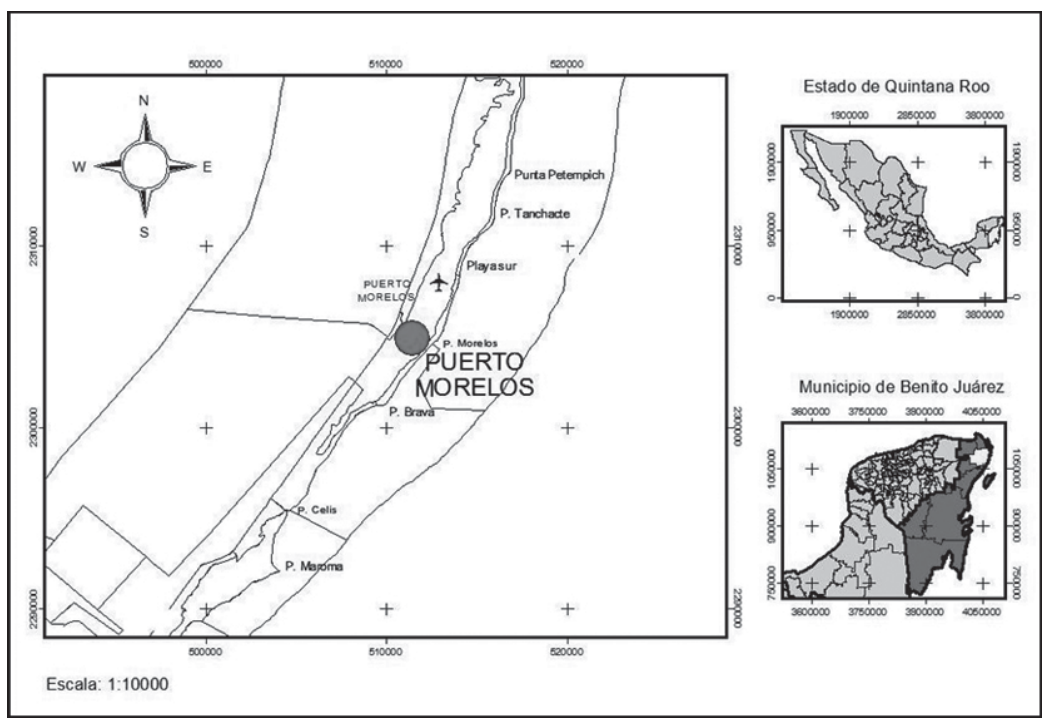

Fuente: Elaboración propia

La pesca trajo consigo la conformación de una cultura que se expresó a través de los medios de producción y de los medios para la satisfacción de necesidades así como también mediante costumbres, usos (culturales y del espacio) y el lenguaje, mismos que se afianzaron a la vida cotidiana reorganizando los espacios de vida para configurar el paisaje.

El paisaje pesquero mostró sus primeros indicios cuando en el escenario económico de la región aparecen instituciones como el Departamento de Pesca, el Fideicomiso para el Otorgamiento de Créditos a las Sociedades Cooperativas Pesqueras (posteriormente BANPESCA) y el propio gobierno federal, quienes se encargaron de la organización de la actividad, la legalización de las áreas de pesca, la tecnificación del capital humano y de la promoción de algunos apoyos económicos.

El plan de gobierno de consolidar un sector pesquero de tipo comercial conformado por sociedades cooperativas surtió efecto en este poblado, durante esta etapa se constituyo también la Sociedad Cooperativa Pescadores de Puerto Morelos; el arduo trabajo realizado por los pescadores de este poblado les permitió con el tiempo adquirir algunos créditos para la modernización de la actividad, de tal forma que, al espacio de trabajo fueron incorporadas las embarcaciones de fibra de vidrio y motores fuera de borda, redes de fibra sintética y el muelle que fue acondicionado para una pesca de mayor intensidad. 
Tanto el litoral como el muelle tuvieron como uso elemental que fue el trabajo, ahí se desarrollaban las actividades para el sustento familiar y de abastecimiento al mercado. Éstos también tuvieron algunos usos particulares y condicionados, por ejemplo, el muelle constituyó el espacio de convivencia de los pescadores después de la jornada de trabajo, la vida doméstica se extendió hasta este lugar donde muchas las familias dormían en aquellas temporadas donde el calor era poco soportable.

El Estado como regulador de la actividad buscó la tecnificación de la fuerza de trabajo, fue con el apoyo de la Secretaría de Educación Pública y el Departamento de Pesca que se incorporaron al espacio de trabajo dos centros de investigación y una institución educativa (INE, 2000).

$\mathrm{Al}$ establecerse estos servicios comienzan a incorporarse otros usos en la vida cotidiana que expresan los intereses del sistema dominante por el conocimiento del litoral. Tanto estudiantes como profesores e investigadores hicieron de éste un lugar para la adquisición y generación de conocimientos que permitieran un supuesto manejo productivo de los recursos del mar; la impronta ideológica de estos usos particulares estuvo determinada por la búsqueda de integrar este Territorio al desarrollo nacional a través de su biodiversidad marina. La presencia de estas instituciones en la vida cotidiana, institucionalizó otros usos como por ejemplo, el uniforme entre los estudiantes y trabajadores de los centros de investigación, el uso de la plaza central como centro de ceremonias, etc.

El impulso a la pesca comercial y la diversificación de los servicios educativos fueron dos factores determinantes en el incremento de la población, la generación de empleos por la actividad propició una oleada migratoria de trabajadores ${ }^{4}$ que trajeron consigo una serie de transformaciones sobre el mundo de los objetos a razón de la demanda de viviendas y otros servicios públicos (banquetas, escaso alumbrado público, agua potable), pero su presencia también transformó de manera importante los usos y el lenguaje de la vida cotidiana.

Si bien, antes del impulso a esta actividad ya existía un espacio doméstico y vecinal conformado por viviendas tradicionales construidas con materiales obtenidos de la naturaleza y ubicadas de manera arbitraria en torno al muelle, durante esta época la Dirección General de Terrenos Nacionales junto con el Departamento de Asuntos Agrarios y Colonización y el Fondo Nacional del Fomento Ejidal (FONAFE), promovió la creación del fundo legal (1973) con la finalidad de reorganizar, regularizar, expandir y consolidar este asentamiento humano.

En este proceso de fraccionamiento del espacio vecinal, hubo quienes tuvieron que abandonar sus antiguas prácticas de «habitar el espacio» para doblegarse a un modelo urbano impuesto por el Estado que dictó nuevas normas, derechos de acceso y formas de aprovechamiento no sólo del suelo sino también de los recursos naturales. 
De una manera más «ordenada», el estilo de vida costero (en relación con los objetos y la posesión de bienes) y los usos (culturales y del espacio) continuo manifestándose a través de las viviendas de una sola habitación, cultivos y animales de traspatio, hamacas y lavaderos fuera de la casa, caminos de terracería, animales de carga como principal transporte, escaso alumbrado público, etc. constituyeron el común denominador del paisaje costero de este pueblo.

Al tiempo que la actividad pesquera era modernizada, el paisaje también se configuraba a partir de la dotación de infraestructura: agua, luz eléctrica y, principalmente, se le dio un fuerte impulso a la construcción del camino que comunica al poblado con la que actual carreta federal 307 Chetumal-Cancún, la finalidad era dar salida a los productos del mar hacia las empacadoras ubicadas de manera estratégica en el territorio quintanarroense.

Con ello, los autobuses de pasajeros con destino a Mérida así como aquellos que la hacían de mercaderes ambulantes e incluso los taxis, comenzaron a formar parte aquellos objetos que le permitieron a la población local el acceso a otros bienes de consumo y al uso de otros servicios en el exterior. La población cambió los viajes en animales de carga, las caminatas por los senderos y los viajes en pequeños buques por el uso del transporte; la alimentación y la vestimenta se diversificaron gracias a la llegada de vendedores.

Para la mayor parte de las familias la playa o la plaza central era el espacio para pasar el tiempo libre. Recuerdan las tardes recogiendo icacos y uvas de mar a la orilla de la playa, recolectando cocos o «emplayando ${ }^{5}$ « objetos traídos por el mar. Además de su uso elemental, estos espacios tuvieron otros usos particulares y condicionados, por ejemplo, la gente se reunía en la plaza para observar los juegos de beisbol organizados por algunos miembros de la población o también para llevar a cabo las celebraciones religiosas o cívicas; en sentido estricto, éstos eran los espacios de los acontecimientos, de los mitos, de la historia y de las relaciones sociales.

En Puerto Morelos la modernización de las vías de comunicación permitió el acceso a otros bienes de consumo que se incorporaron rápidamente a la cotidianidad, por ejemplo, la televisión o la radio, el periódico comenzó a llegar semanalmente y el desplazamiento de pasajeros hacía llegar las «noticias "a este poblado. A través de estos medios, el discurso nacionalista resaltaba a la actividad pesquera como la principal vía para el «desarrollo» de la región; al lenguaje se incorporaron discursos que destacaban la importancia de los pescadores en el desarrollo regional y nacional, los pescadores organizados en cooperativas eran los únicos mexicanos que tenían derecho a capturar las especies de «mayor importancia comercial» en el país, así como también se mencionaba que el crecimiento estaba en manos de «los verdaderos trabajadores del sector pesquero” (Alcalá 2003). 


\section{La coyuntura turística: la incorporación del paisaje turístico a los espacios de vida cotidiana}

La estrategia económica que, de manera gradual, fue elaborando un conjunto de políticas, instrumentos y acciones para hacer de las actividades agropecuarias un sector fundamental en el proceso de industrialización del país, estaba llegando a su fin.

Lo que se requería era impulsar otras actividades económicas que, basadas en la explotación de los recursos naturales, participaran en la transformación de la entidad en términos demográficos, económicos, políticos y sociales; la idea era generar las condiciones para que ésta y otras entidades participaran de la nueva estrategia nacional que proponía impulsar la modernización de la economía mexicana con base en la redefinición de la participación del Estado, la desregulación económica y la apertura comercial.

La actividad turística comenzó a desarrollarse en Quintana Roo a partir de la década de los setenta, su surgimiento no fue una acción deliberada por parte del gobierno de aquel momento y de los subsecuentes; por el contrario, esta actividad fue impulsada como una herramienta para crear un grupo empresarial que pudiera capitalizarse y generar la diversificación económica de esta región que, a pesar del impulso a la pesca comercial, estaba prácticamente despoblada y su riqueza natural había sido escasamente explotada (Macías y Arístides, 2009).

Así, el Estado mexicano se involucró de lleno en el impulso de la actividad turística en ésta y otras regiones del país, el resultado de este proceso de tecnificación de la actividad fueron los Centros Integralmente Planeados (CIP's) entre ellos Cancún (1974). El modelo turístico de masas bajo el cual se desarrolló este destino, se dispersó por la zona costera de la región norte del Estado trastocando no sólo los recursos naturales de la región sino también el entorno social de los diferentes poblados.

\section{El espacio laboral: los objetos, los usos y el lenguaje del turismo}

Aunque se aborda el espacio de trabajo puerto morelense desde lo microsocial, es importante considerar que su configuración es producto de los procesos de mundialización y de restructuración económica que se pusieron en marcha desde principios de la década de los ochenta hasta la actualidad a nivel nacional. Estos procesos de mundialización y apertura de mercado comenzaron a transformar los métodos de trabajo, de producción y, por tanto, la organización de los espacios y el paisaje de la producción a favor de una actividad económica -en este caso el turismo- que prometió integrarlo a la “modernización”. 
Tras la puesta en marcha de algunas políticas neoliberales y el desarrollo del turismo, las instituciones que regularon el uso y aprovechamiento del espacio y los recursos de la costa durante el modelo de sustitución de importaciones comenzaron a debilitarse; fue así que han surgido diversas organizaciones administrativas, dependientes y autónomas, estatales y privadas que participan de la forma en cómo la población local debe asumir el turismo para propiciar la reproducción del sistema dominante en los diferentes espacios de la vida cotidiana a partir de la incorporación de diversos objetos, usos y el lenguaje del turismo.

Aquel espacio de trabajo centrado en torno al muelle y en el litoral comenzó a expandirse al norte, al sur y hacia la segunda línea de la costa. El alto costo de la tierra, las pocas oportunidades para los pobladores locales y la propiedad privada de lotes y viviendas a raíz del desarrollo del turismo dio lugar a un importante mercado de tierras que permitió el surgimiento de un grupo de empresarios turísticos locales y externos que incorporaron al espacio de trabajo tiendas de artesanías y souvenirs, joyerías, restaurantes de comida internacional, hoteles boutique, agencias de viajes, casas de cambio, arredadoras de autos, entre otros negocios menores.

Muchos de estos objetos incorporados guardan características arquitectónicas tradicionales (palapas, fachadas de madera, plantas ornamentales típicas, construcciones en su mayoría de un solo piso) que recuerdan el antiguo paisaje pesquero; sin embargo, no son más que una estrategia empresarial para diferenciar este destino de otros como Playa del Carmen o Cancún que se caracterizan por mantener una tendencia vanguardista en sus construcciones. A pesar de su imagen tradicional, los servicios turísticos en este poblado se caracterizan por ser bastante personalizados y exclusivos, características que son un importante atractivo para aquellos turistas europeos que permanecen por largas temporadas en este destino.

Dado que el espacio de trabajo se convierte en un espacio compartido entre la actividad pesquera y la turística, la imagen urbana e infraestructura turística durante este modelo de desarrollo se ha convertido en una herramienta importante para promover paisajes prefigurados que «turistifican» la identidad local; la Delegación con apoyo del gobierno municipal se ha dado a la tarea de incorporar al espacio laboral ciertos objetos como el alumbrado público, pavimentación, banquetas, botes de basura, señalización turística, semáforos así como también la construcción de ventanas al mar ${ }^{6}$, además de que otorga el servicio de seguridad pública que se concentra especialmente en éste espacio turístico.

La Delegación junto con otros organismos de orden municipal, han otorgado permisos a taxistas y prestadores de transporte público y colectivo, bancos, tiendas de autoservicio para que se incorporen al espacio de trabajo y, finalmente, formen parte de la vida cotidiana de los pobladores.

El litoral dejó ser un espacio exclusivo para la pesca, las políticas de conservación en torno a los recursos del mar comenzaron a surgir un con- 
junto de organizaciones y/o instituciones interesadas en el aprovechamiento turístico del litoral, específicamente, del arrecife coralino. El Estado como elemento de control ideológico y político interviene con una posición reguladora a través de la Comisión Nacional de Áreas Naturales Protegidas (CONANP) quien al declarar al arrecife como área natural protegida agrega al espacio de trabajo embarcaciones especiales para el monitoreo y salvaguarda del recurso, elementos de señalización como boyas marinas que delimitan las zonas navegables e incluso apoya en la creación de un programa de manejo del recurso.

Este organismo también regula los permisos para que la Cooperativa de Prestadores de Servicios Náuticos de Puerto Morelos, la Cooperativa Pescadores así como empresarios locales y externos (hoteleros y restauranteros principalmente) aprovechen turísticamente el recurso; sin embargo, éstos últimos han sido los más favorecidos por lo que han incorporado al litoral modernas embarcaciones con adaptaciones y equipos necesarios para brindar servicios de snorkel, buceo y tours al turista ${ }^{7}$.

Al transformarse el uso elemental del espacio de trabajo también surgen diversos usos particulares, los cuales no son una cuestión arbitraria, por el contrario, se trata de usos particulares que llevan aparejado el peso ideológico que las instituciones y/o organizaciones han querido darle al desarrollo del turismo en este poblado. Aun cuando el turismo es presentado por éstas como una actividad para todos (incluidos los pobladores locales), el cómo, dónde y por quiénes se usan los espacios y los objetos presentes en este espacio denota un comportamiento ideológico inculcado por los objetos institucionales y organizacionales del turismo.

El muelle que era un espacio casi de uso exclusivo para los pescadores y pobladores locales, con la expansión del turismo ha adquirido usos particulares relacionados con el aparcamiento de embarcaciones destinadas para los turistas, lugar para el avistamiento y alimentación de aves, pesca recreativa, escenario central del torneo anual de pesca y, con las nuevas formas de organización de la pesca y la actividad náutica se convierte en un espacio para el aparcamiento de embarcaciones con permiso por parte de la delegación y la CONANP, siendo éste último sólo uno de los usos condicionados de este lugar.

El arrecife cuyo uso elemental era el de la pesca, ha quedado divido en diversos uso particulares establecidos en el Programa de Manejo del Parque $^{8}$, mismos que han derivado en un usos condicionados del recurso; sobre todo, en aquellos para el aprovechamiento de las zonas destinadas al turismo, dicho programa establece que se requiere de la certificación técnica en buceo y una serie de permisos emitidos por la Secretaria de Medio Ambiente y Recursos Naturales (SEMARNAT).

El desarrollo del turismo también ha traído consigo un uso generalizado de códigos urbanos; a través de su carácter publicitario, el lenguaje del turismo se ha venido introduciendo en los diferente contextos sociales 
como un agente homogeneizador. Las imágenes, en su componente particularmente visual, han jugado un papel preponderante en la transmisión de formas específicas de uso de los espacios cotidianos. La vida cotidiana, en sus diferentes espacios, se ha convertido en un mercado de símbolos mediado, en gran parte, por supuestos ideológicos que se sirven del gusto y la moda.

A pesar de que aún existe una tendencia que defiende los códigos locales, el turismo ha dado lugar a la difusión de los modelos de consumo de la cultura dominante a través de un complejo intercambio de relaciones simbólicas y mediáticas ${ }^{9}$. Así encontramos que, a pesar de que aun existe una tendencia bien marcada que defiende los códigos locales, los pobladores se han convertido en promotores del la actividad, en su lenguaje existen modos de enunciación y de razón encaminados a privilegiar los objetos y los usos de los espacios cotidianos por parte de los turistas y las empresas turísticas.

A través del mundo de los objetos, usos y lenguaje se visualiza que la actividad turística en este poblado ha sido orientada a favorecer la incursión de las empresas turísticas al espacio de trabajo; el Estado a través de las diversas instituciones ha generado toda una serie de condiciones económicas y políticas así como un conjunto de restricciones respecto al aprovechamiento del espacio y los recursos naturales que excluyen a la población local y favorecen a las empresas turísticas (especialmente trasnacionales), quienes han contribuido de manera determinante en la configuración de un paisaje turístico que promueve un uso exclusivo por aquellos actores que cumplen con las estipulaciones solicitadas por las organizaciones del turismo y que, al mismo tiempo, denota una incipiente concentración de servicios y actividades turísticas en el espacio de trabajo, mismas que se fundamentan en un proceso de segregación y exclusión socio-espacial.

\section{Espacio doméstico y vecinal: objetos, usos y el lenguaje}

El modelo turístico centrado en la costa de sol y playa que se viene desarrollando desde la década de los setenta en la región con la creación de Cancún ha traído consigo crecimiento demográfico, migración ${ }^{10}$ y transformaciones urbanas; las oportunidades de empleo que ofrece esta región así como el desarrollo de un importante mercado de tierras de lotes y viviendas de la franja costera no sólo han alterado la fisonomía del espacio doméstico y vecinal de este poblado, sino también sus referentes y relaciones locales así como la diversificación de las formas de vida.

Aquel espacio doméstico y vecinal que se traslapaba con el espacio de trabajo durante el paisaje pesquero, ha quedado fragmentado y, prácticamente, desplazado de la primera línea de la franja costera hacia la tercera -conformado por extranjeros, intelectuales, investigadores, artistas plásticos y en menor medida nativos- y extendiéndose detrás de ésta con la conformación de otros asentamientos humanos (Colonia Joaquín Cetina Gasca, 
Villas Morelos I y II y, Zona Suburbana) donde actualmente viven las familias de los antiguos pescadores, palaperos, chicleros y población migrante; no así ha sucedido con la llamada Zona Suburbana donde se han asentado en su mayoría extranjeros como producto de la compra-venta de terrenos de propiedad ejidal.

Figura 3. Asentamientos humanos en Puerto Morelos.

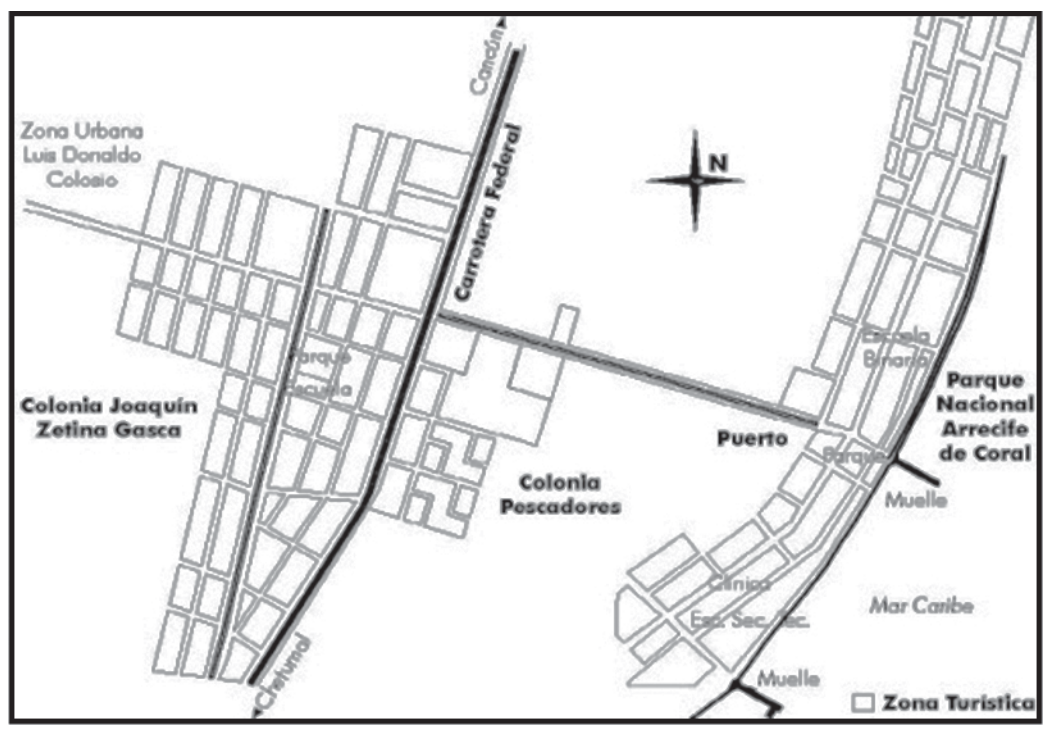

El espacio doméstico que va de la tercera línea de la franja así como de los asentamientos humanos detrás de ésta aún guardan algunos rasgos rurales (calles sin pavimentar, casas de materiales no duraderos); no obstante, las heterogéneas y desiguales condiciones sociales, económicas y culturales de la población así como los constantes problemas de inseguridad han provocado que algunos habitantes incorporen al mundo de los objetos bardas, portones, rejas, patios traseros, cocheras, jardines, divisiones al interior, decoraciones (pintura, elementos arquitectónicos) y, que se eliminen otros de uso tradicional como las cocinas de humo, cultivos de traspatio, palapas o los lavaderos frente a las casas.

Como se ha mencionado, el desarrollo turístico convirtió a este poblado en un polo de atracción de nuevas corrientes migratorias; para las empresas inmobiliarias y de créditos (INFONAVIT, FOVISSTE y Villas Morelos II) esto representó una importante fuente de negocio que ha permitido incorporar al paisaje doméstico dos conjuntos habitacionales, los cuales cumplen una función importante: mantener la fuerza de trabajo tras 
el desarrollo turístico para cuando las empresas -no sólo de Puerto Morelos sino de otros destinos de la región- la requieran.

El espacio doméstico no ha perdido su uso elemental que es el "habitar”, sin embargo, con la dinámica laboral -que exige amplias jornadas de trabajo y la integración de la mujer al mundo laboral- este espacio ha adquirido como uso particular: el de "dormitorio". En otros casos, las pocas alternativas económicas han inducido a los pobladores a adaptar sus casas para la renta de habitaciones a trabajadores temporales, particularmente, los de la construcción; lo anterior, es sólo uno de sus usos condicionados, pues de ser un lugar habitado tradicionalmente por la familia ahora es habitado por gente externa.

Anteriormente, el espacio doméstico se extendía hacia el espacio vecinal durante una celebración o cualquier tipo de reunión, con la llegada de gente de diversas partes del país la relación que mantenían ambos espacios se ha fracturado. La itinerancia a la que ha sometido el mercado laboral a la población migrante redujo las posibilidades de construir relaciones intensas y duraderas al exterior del espacio doméstico. Por tradición y remembranza, algunos pobladores nativos han conservado sus espacios domésticos en la franja costera pero al igual que en el resto de los asentamientos estos son, muchas veces, usados como dormitorios o casas de renta; en cuanto se les presenta la oportunidad venden sus casas a extranjeros para negocios turísticos o como residencias temporales, lo cual rompe con el uso elemental de este espacio.

Lo cierto es que el espacio doméstico y vecinal -específicamente el de la tercera línea de la franja- se ha convertido en un espacio de uso particular de algunos grupos sociales: extranjeros y residentes de otras partes del país con cierto status económico, social y cultural (artistas, intelectuales, científicos).

La presencia de estos actores sociales y la influencia de las numerosas inmobiliarias ${ }^{11}$ se ha visto reflejada en la configuración del paisaje; últimamente se han propagado por el espacio costero construcciones de tres e incluso cuatro pisos, fachadas modernas y estilos vanguardistas e incluso se ha comenzado a generalizar la presencia de complejos habitacionales bardeados con casetas y cámaras de seguridad, se han retomado las palapas y la palma de coco pero como elementos ornamentales, protecciones en contra de los huracanes, la implementación de flora no endémica, entre otros elementos que han configurado un paisaje exclusivo para una clase con un nivel económico alto, lo que le confiere un uso condicionado porque ha quebrantado la usanza tradicional del mismo.

En Puerto Morelos la construcción de carreteras y la entrada de diversos medios de transporte para permitir el desarrollo del turismo también ha dado lugar a la incorporación de diferentes satisfactores materiales de las necesidades básicas de la población local, encontramos que de la tercera línea de la franja hacia atrás aumentaron considerablemente las tiendas 
de abarrotes, pollerías, farmacias, tortillerías recauderías, cibercafés, peluquerías, talleres eléctricos y mecánicos, cerrajerías, centros de salud, escuelas primarias y, sobretodo, aquellos servicios funcionales a la fuerza de trabajo como lavanderías, cocinas económicas, puestos ambulantes de comida, transporte público colectivo, guarderías, entre otros.

Las transformaciones en el paisaje del espacio vecinal, afectaron de manera intensa y diversa la vida de los pobladores locales, este espacio como parte estructural de la vida cotidiana perdió de manera importante sus cualidades para la convivencia; con las actividades demandas por el crecimiento urbano y las olas migratorias producidas por el turismo se redujeron la posibilidades de entablar relaciones vecinales; la brecha económica, social y cultural existente entre vecinos se hizo cada vez mayor, alterando y, algunas veces, nulificado la posibilidades de los encuentros. Hoy en día, los juegos infantiles en las calles, los encuentros «cara a cara» con la intención de conservar o actualizar las tradiciones (posadas, novenarios, etcétera), la unión y solidaridad, ya no son tan posibles debido a que éste espacio ha adquirido diversos usos condicionados.

La supuesta imagen tradicional del pueblo ha dado lugar a que éste sea usado, particularmente, por ciertos grupos sociales; por ejemplo, los hoteleros ofrecen a sus huéspedes tours por el espacio vecinal para conocer la forma de vida «tradicional» de quienes lo habitan, se puede hablar de una dominación cada vez mayor de la actividad turística sobre éste espacio e incluso la forma en cómo se recorre el espacio ha comenzado a cambiar debido a la dispersión de los servicios (escuela, mercados, trabajos, etcétera).

\section{Espacio de ocio: objetos, usos y el lenguaje turístico}

Con el auge del capitalismo y el surgimiento del turismo de masas, la diversión comenzó a estar cada vez más relacionada con la forma de consumo y los intereses de la clase dominante. Desde la postura de Marcuse (1985), las actividades que anteriormente estaban reservadas a las clases dominantes, hoy han quedado al alcance de quienes pertenecen a segmentos de niveles de ingresos cada vez más bajos.

No obstante, para las poblaciones receptoras el esparcimiento y el uso del tiempo libre ha adquirido otra dimensión: sus recursos naturales y espacios turísticos se han convertido en recursos con un valor económico que, una vez transformados y/o acondicionados, se convierten en medios de producción para satisfacer las necesidades de ocio y recreación de otros (turistas).

En el caso de Puerto Morelos, aquellos espacios que representaban los lugares de ocio para la población local han sido en su mayoría acaparados por empresarios para convertirlos en un producto más para el turismo. La población local (pobladores nativos y, especialmente, migrantes) no sólo ha quedado al margen de su aprovechamiento económico sino también de 
su disfrute durante el tiempo libre. En este lugar, los espacios de ocio han adquirido un valor económico y un status de «exclusivo» -para el turista-, las instituciones (gobierno municipal y estatal) en conjunto con empresarios turísticos se han valido de diferentes políticas, normas y reglamentos ${ }^{12}$ respecto a la conservación, uso del suelo y la imagen urbana para dominar, casi por completo, los espacios de ocio.

Ante la falta de medios de comunicación (carreteras y transporte) durante el paisaje pesquero, la plaza central, la playa y el arrecife constituyeron tres de los espacios de convivencia y encuentro, de relaciones y contactos humanos más importantes para la población. Eran considerados espacios abiertos y públicos donde la gente podría reunirse para compartir experiencias, jugar o simplemente para «pasar el rato»; debido a su ubicación geográfica, biodiversidad y funcionalidad para la actividad turística estos espacios comenzaron a ser objeto de la transformación y acaparamiento por parte de los organismos, instituciones y actores sociales que actualmente orientan la actividad turística en el poblado.

Las políticas municipales tanto urbanas como ambientales, han sido un elemento fundamental en la determinación de los objetos incorporados y en los usos que se hace de ellos; el tipo y dimensiones de las construcciones, ocupación o giro, requerimientos arquitectónicos para su integración a la imagen urbana así como también las especificaciones técnicas para el disfrute de los recursos naturales, son producto de una serie reglamentos y normatividades que -llevando implícito los requerimientos de una clase social dominante- “ordenan” el paisaje costero para un tipo de turista quien exige el disfrute de un ambiente "agradable” que implica no sólo una limpieza física del lugar sino también social.

Si bien, estos espacios aún no pierden su uso elemental, ciertos integrantes de población local así como empresarios e incluso turistas han venido otorgándoles ciertos usos particulares, por ejemplo, la plaza central ha sido adaptada en algunas ocasiones como sede de exposiciones artísticas o eventos musicales, la playa como espacio para el descanso y de observación de la riqueza natural y, algunas zonas del arrecife se han destinado para uso exclusivamente turístico.

Lo cierto es que a través de diversos reglamentos el gobierno municipal ha venido controlando los usos que la población hace de estos espacios, prueba de ello son aquellos que regulan -aunque en realidad prohíbenla presencia de vendedores ambulantes en playas o plazas públicas, otros que impiden pasear a las mascotas en la playa, también están los que regulan el comportamiento del poblador y/o visitante en la vía pública al prohibir que ingieran bebidas alcohólicas u organicen bailes en calles o plazas; todo esto bajo el discurso de mantener el orden.

El Estado se ha asociado con el sector privado y ha ingeniado toda una serie de restricciones para conseguir la "limpieza” física y social de estos espacios, misma que va desde la homogeneización del pai- 
saje hasta la exclusión de la población local y migrante (oaxaqueños, tabasqueños, chiapanecos) por considerar que sus hábitos causan mala imagen al destino.

Lo que la realidad evidencia, es una paranoia por lograr el control urbano, manifiesto en el aumento de regulaciones y restricciones -principalmente dirigidas a la población local-respecto al uso del espacio de ocio que ahora es turístico; ese control responde al temor de los empresarios por lograr que este espacio sea atractivo y se "vea bien” para el turista, pero también al propio temor del gobierno municipal de que a razón de su imagen urbana este destino no figure dentro de los más visitados de la región.

Otra estrategia adoptada por el gobierno municipal ha sido el desplazamiento de la vivienda hacia la periferia y, con ello, la dotación de servicios públicos, mismos que incluyen servicios de educación, ocio y recreación como parques, plazas, bibliotecas, canchas deportivas e incluso un auditorio para los eventos y/o celebraciones públicas; lo anterior significa mantener a la población local que no se encuentra inserta en la prestación de servicios turísticos fuera de aquellos espacios (franja costera) de ocio que ahora son turísticos.

La segregación de los espacios de ocio -aunque también del doméstico y vecinal_, ha venido aparejado no sólo de segregación socio-espacial sino también de la estigmatización del "otro", intensificando con ello la exclusión social de la que actualmente son objeto los pobladores locales y migrantes que habitan tras la franja costera. De acuerdo con Sabatini, Cáceres y Cerda (2001), las áreas con un alto grado de estigmatización social se prestan para la producción y reproducción de prácticas sociales anómicas y de conflictos con altos niveles de violencia, en el caso de Puerto Morelos, el uso de los espacio y el tiempo libre de adolecentes y adultos (en su mayoría hombres), especialmente en las Colonias tras la franja, se relaciona cada vez más con el consumo de bebidas alcohólicas en parques y canchas deportivas.

\section{Conclusiones}

La necesidad imperante de integrar el territorio quintanarroense a la modernización, tuvo como resultado el desarrollo de una economía basada en la pesca que dio lugar a una fuerte concentración de la cotidianidad sobre la costa; el Gobierno Federal -a través de las diferentes dependencias gubernamentales- en su papel de Estado desarrollista afianzó ciertos patrones políticos, económicos, sociales, culturales que -a través de la incorporación de toda una serie de objetos, usos y del lenguaje- permitieron que la vida cotidiana de este pueblo se estructurara bajo el orden hegemónico de ese momento histórico.

La puesta en marcha del modelo neoliberal a nivel nacional y el desarrollo del turismo en la región trajeron consigo importantes ajustes 
estructurales no sólo en la economía de este poblado sino también en la de otros dedicados a la pesca artesanal. Las libres fuerzas del mercado comenzaron a tener un papel más activo en el uso aprovechamiento de los espacios costeros, en detrimento de la participación del Estado. Los recursos naturales y el espacio adquirieron un valor económico pero no por su importancia productiva sino por sus características ambientales, socio-espaciales, ubicación y potencialidad estratégica para el desarrollo del mismo.

El paisaje configurado en torno a la pesca, mismo que fue punta de lanza para la integración de este poblado al desarrollo estatal, se convirtió en un obstáculo para la apertura a la inversión extranjera y la apropiación y valorización de espacio por parte del capital turístico. Con el desarrollo del turismo, el espacio vecinal, doméstico y de ocio fueron desplazados tras la franja costera, se convirtieron en espacio espacial y socialmente bien diferenciados respecto al espacio turístico: la creación del fundo legal, el otorgamiento de la propiedad privada de la tierra y la especulación de la misma así como la migración y la creación de algunas políticas públicas respecto al uso del suelo fueron factores determinantes en la desestructuración y la dispersión espacial de esa vida cotidiana que se configuro durante el paisaje pesquero.

La industria turística, a través de las instituciones y empresas turísticas que actualmente tienen un importante dominio en el escenario económico, político y social no sólo del poblado sino de la región, han venido imponiendo el qué, cuándo, dónde, cómo y quiénes pueden incorporar ciertos objetos, usos y formas de comunicación sobre esos espacios de la cotidianidad que han adquirido un valor desde el punto de vista turístico y sobre aquellos que indirectamente sirven a la actividad. El modelo bajo el cual ha venido desarrollándose el turismo en la franja costera responde a los intereses de la clase dominante, es ésta quien valiéndose de las políticas públicas en materia de ordenamiento e imagen urbana así como de aquellas relacionadas con la conservación del entorno natural, han diseñado un conjunto de instrumentos -reglamentos y normas- que actúan como estrategias y mecanismos de control sobre aquellos espacios de vida que, dada la reestructuración económica, han resultado funcionales a la actividad turística.

El avance del modo de producción capitalista a través del desarrollo de la actividad turística ha provocado que la población puerto morelense participe de esta nueva dinámica económica a través de la vida cotidiana, primeramente, a partir de dos campos que corresponde al mundo de los objetos: mediante la incorporación de los medios para la producción (hoteles, restaurantes, bares) y a través del consumo, mismo que está relacionado con la satisfacción de las necesidades humanas (vivienda, salud, esparcimiento).

En este sentido, es el Estado -en su aparente papel de regulador- se constituyó en uno de los principales orientadores y organizadores de la actividad, al incorporar al paisaje ciertos objetos del turismo que hicieron y 
hacen cada vez más atractivo y más apropiable el espacio costero por parte de las empresas de alimentos y bebidas, hospedaje, inmobiliarias y empresarios menores locales y externos, quienes por cierto han emprendido un notable proceso de deslocalización empresarial ${ }^{13}$.

Las instituciones gubernamentales en asociación con las empresas turísticas como orientadores y organizadores de la actividad, han desempeñado un papel importante en la homogeneización del paisaje a partir de la fragmentación y homogeneización de los espacios de vida cotidiana. Por un lado, la apropiación de los espacios y la diversificación del mundo de los objetos, los usos y el lenguaje debido a la multiplicidad de servicios turísticos han contribuido a la homogeneización del paisaje mediante la exaltación de una arquitectura y símbolos que, aunque rescata algunos elementos tradicionales, se ha convertido en un objeto-evento destinado a una sociedad ávida de «consumir espectáculo» (Yory, 2006:103).

Y por el otro, la homogeneización se ha dado a partir de la aplicación de una serie de regulaciones en materia de ordenamiento e imagen urbana y de conservación del entorno natural que han traído consigo la incorporación al paisaje de un conjunto de prototipos arquitectónicos formales, que además de promover una pretendida homogeneización física también han otorgado una especie de «libreto» que señala, no sólo cómo apropiarse de los espacios de la cotidianidad sino como ocuparlos y hacer uso de ellos.

Para este trabajo de investigación, la homogeneización del paisaje no es la simple homogeneización de la escenografía, por el contrario, se trata de la transformación y universalización de las pautas de producción y de consumo que vienen acompañadas de un conjunto de usos particulares y/o condicionados y formas de lenguaje cargados de la ideología dominante y que dan estructura a la vida cotidiana y, por consiguiente, al paisaje.

Los cambios político, económicos y sociales traídos por el cambio en el modelo económico, la liberalización de los mercados de uso del suelo que han fomentado la especulación inmobiliaria y las oleadas migratorias atraídas por el desarrollo turístico, dieron lugar a una conformación bastante heterogénea de la población que, no sólo se manifiesta a través de la diferente carga cultural sino de la forma tan diversa que hacen de los espacios, según las características y diferenciaciones entre los grupos sociales que los construyen, los habitan, usan, simbolizan y disfrutan.

La tendencia de los grupos sociales a concentrarse en determinados espacios de la costa de acuerdo a su condición social, no sólo ha fragmentado el espacio de acuerdo a sus características físicas y a las pautas de habitar el espacio sino también ha producido una fragmentación social que se manifiesta en la discriminación y exclusión del “otro”. El espacio vecinal situado tras la franja costera se ha convertido en las zonas estigmatizadas socialmente, de manera general, existe una depreciación de las personas dependiendo de si habitan en la franja o detrás de ella. 
Sin mencionar aspectos como el nivel educativo, ingresos y otros relacionados propios a la calidad de vida, es evidente que en las Colonias ubicadas tras la franja costera son más frecuentes patrones de conducta «desviadas» como el alcoholismo, drogadicción, abandono familiar, embarazos en la adolescencia y deserción escolar entre otros; lo cual ha contribuido a configurar paisajes de exclusión y fragmentación social que, por supuesto, no forman parte de la oferta para el turismo pero sí son una preocupación para la imagen turística del lugar.

Las instituciones y empresas que orientan y organizan la actividad turística en este poblado, prácticamente se ha apropiado de la franja costera por ser el espacio con mayores ventajas naturales, económicas e infraestructurales para la actividad turística; sin duda alguna, la especulación ha sido ese mecanismo mediante el cual el capital ha reservado ciertas áreas para uso potencialmente lucrativo, creando un espacio turístico costero volcado, casi por completo, hacia el consumo de bienes, servicios y paisajes. 


\section{Notas}

${ }^{1}$ La valorización se refiere «al conjunto de las condiciones espaciales universales de reproducción de los modos de producción...» (Robert y Messias da Costa 2009:107), lo anterior puede ser interpretado como la creación de las condiciones no sólo de accesibilidad e infraestructura sino también de otro tipo (finanzas, gobierno, formación de recursos humanos, capacidad tecnológica) que permitan a los inversionistas interesados hacer de los espacios rurales no sólo espacios para la producción sino para el consumo del espacio y del paisaje mismo.

${ }^{2}$ Los usos particulares regulan la vida y las acciones de clases, constituyen formas en las que se expresan los intereses, los fines, los sistemas de valores, la ideología de integraciones determinadas; por tanto, es fuertemente estratificado y heterogéneo. Los usos condicionados son característicos de grupos o de un grupo relativamente grande de personas, pero cuya observancia no representan una condición necesaria para que el particular viva en conformidad a las normas de los relativos a su puesto en la división del trabajo. Y finalmente los usos personales, los cuales dependen del «ser así» antropológico del particular, por lo tanto, es fuertemente indicativo de la personalidad y determinan el ritmo de la vida.

${ }^{3}$ Ciertos objetos son para la satisfacción de necesidades y, otros, que son parte del desarrollo de los medios de producción, pero ambos con la capacidad de transformar el medio físico doblegando la naturaleza a las necesidades de la reproducción del capitalismo.

${ }^{4}$ Para la Escuela Secundaria Técnica Pesquera se contrató una plantilla de 13 empleados y, 108 para el Centro de Investigaciones de Quintana Roo, algunos de ellos llegaron con sus familias (Entrevista realizada el 22 de septiembre de 2009 al actual director y uno de los primeros estudiantes de esta institución).

${ }^{5}$ La gente hace uso de esta palabra cuando quiere referirse a recoger objetos (madera, plásticos, etc.) traídos por el mar, que solían ser útiles para el acondicionamiento y/o construcción de sus viviendas.

${ }^{6}$ http://institutoforestal.qroo.gob.mx/portal/WebPage.php?Pagina=NotaVoc.php\& IdNota $=4769$

${ }^{7}$ En siguiente dirección electrónica http://www.conanp.gob.mx/acciones/permisos.php, la CONANP publica un listado con los nombres de las personas físicas y morales que han sido beneficiadas con los permisos y autorizaciones para la prestación de servicios y actividades vigentes otorgados para esta área natural protegida.

${ }^{8}$ En el Programa de Manejo del Parque Nacional Arrecifes de Puerto Morelos (2000), se describen diferentes zonas y su ubicación donde, de manera general, pueden realizar actividades de investigación, monitoreo y restauración. Este recurso natural ha quedado zonificado en nueve zonas de aprovechamiento: Zona I. Uso recreativo intensivo, Zona II.Uso educativo e interpretación ambiental, Zona III. Canal de seguridad, Zona IV. Zona para navegación en la laguna arrecifal, Zona V. Zona para navegación, Zona VI. Uso recreativo semi-intensivo, Zona VII. Uso recreativo especial, Zona VIII. Uso pesquero concesionado, Zona IX. Uso científico (INE, 2000: 105-111).

${ }^{9}$ De acuerdo con Yory, la «mediatización» no sólo alude al papel disuasivo y propagandístico de los medios de comunicación sino a la «mediación» de nuestra relación con el mundo 
desde el lenguaje. Simbólicas porque nos expresamos a partir de un sistema de valores desde el cual hacemos patente nuestra aprehensión de la realidad y el mundo (2006:46).

${ }^{10}$ De acuerdo con el Censo de Población y Vivienda de 1980 la población puerto morelense estaba conformada por 672 habitantes. De 1990 al año 2007, la población paso de 1,464 habitantes a 8,695 habitantes, de los cuales se registró que la población nativa asentada en la franja estaba conformada por 257 habitantes; de manera similar, se encontró que en la Colonia Joaquín Cetina Gasca sólo existen 748 habitantes originarios del poblado, el resto nacieron en otra entidad del país incluso en otros países del mundo. Los datos anteriores establecen que la población migrante hacia Puerto Morelos, representa el 70 \% de los habitantes totales, esta cifra está muy por encima de los índices nacional y estatal e incluso es superior al indicador de la Ciudad de Cancún (Censo de población y vivienda 1980, 1990, 2000; SEPLADER 2008).

${ }^{11}$ Entre las empresas inmobiliarias que han acaparado la zona norte de la franja costera puerto morelense están: Mayan Riviera Properties, Itancan S. de R.L. de C.V. y Arrecife Development S. de R.L. de C.V. La primera es una empresa inmobiliaria estadounidense que no sólo opera en Puerto Morelos sino también en la Riviera Maya y en el estado de Yucatán, se especializa en alquileres de casas particulares para vacaciones, en la compra / venta de bienes raíces y en servicios de gestión. La segunda, es una empresa que se ha especializado en el desarrollo de propiedades a lo largo de la Riviera Maya, entre las construcciones más sobresalientes hechas por esta inmobiliaria en Puerto Morelos están dos condominios de lujo «Casitas del Mar» y «Las Tortugas». Y finalmente, Arrecife Development S. de R.L. de C.V. es una empresa de origen estadounidense con sede en Oklahoma que se especializa en la venta de propiedades frente al mar, no sólo tiene presencia en este pueblo turístico sino en otros como Mahahual, Tulum y se ha extendido a Belice y Guatemala.

${ }^{12}$ La vida cotidiana en la franja costera ha sido sometida a una serie de reglamentos que velan sobretodo, por el cuidado de la imagen turística del poblado, por ejemplo, el Reglamento de Anuncios para el Municipio de Quintana Roo (1995), Reglamento para el comercio en la vía pública del Municipio de Benito Juárez, Quintan Roo (2008), Reglamento de Construcción para el Municipio de Benito Juárez, Quintana Roo (2008), Reglamento de Mercados y Centros Comerciales del Municipio de Benito Juárez, 1997; Reglamento de Espectáculos y Diversiones para el Municipio de Benito Juárez, Quintana Roo; Reglamento para la protección de animales domésticos del Municipio de Benito Juárez, Quintana Roo, en este último se establece la prohibición de pasear con animales (perros) en espacios públicos principalmente la playas turísticas

${ }^{13}$ De acuerdo con Molina, la deslocalización empresarial es cuando el grana capital -a partir de la gran empresas-, en la búsqueda de ventajas comparativas, se puede trasladar de un lugar a otro, elegir un punto determinado frente a otros, a partir de una condiciones de producción más flexibles (1998:14). 


\section{Bibliografía}

Alcalá, Graciela (2003), Políticas pesqueras en México (1946-2000): contradicciones y aciertos en la planificación de la pesca nacional, El Colegio de Michoacán, México.

Chávez, Tzintli (2009), “La contemplación del ‘otro’ dentro de espacios turísticos (un enfoque hermenéutico)”, en Revista de Arquitectura, Urbanismo y Ciencias Sociales, Revista del Centro de Estudios de América del Norte, El Colegio de Sonora, México.

Heller, Aganes (1972), Historia y vida cotidiana. Grijalbo, México.

Idem (2002), Sociología de la vida cotidiana, Ediciones Península, Barcelona.

Hiernaux, Daniel (1995), “Tiempo, espacio y apropiación social del territorio: ¿Hacia la fragmentación en la mundialización?”, en Diseño y sociedad No. 5, Revista de la Universidad Autónoma Metropolitana, México.

Hiernaux, Daniel (2006), "La fuerza de lo efímero. Apuntes sobre la construcción de la vida cotidiana en el turismo”, en Lindón Alicia (coord.), La vida cotidiana y su espacio-temporalidad, Antropos, España.

Instituto Nacional de Ecología (2000), Programa de manejo Parque nacional Arrecife de Puerto Morelos, INE, México.

Instituto Nacional de Estadística, Geografía e Informática (1980), Censo General de Población y Vivienda 1980, Instituto Nacional de Estadística, Geografía e Informática, México.

Idem (1990), Censo General de Población y Vivienda 1990, Instituto Nacional de Estadística, Geografía e Informática, México.

Lindón, Alicia (1997), “El trabajo y la vida cotidiana. Un enfoque desde los espacios de vida”, en Revista Economía, Sociedad y Territorio, año/ vol. 1, núm. 001, El Colegio Mexiquense A.C, México.

Macías, R. (NOMBRES) y Arístides, R. (2009), Cancún. Los avatares de una marca turística global, Bonilla Artigas Editores, México.

Marcuse, Herbert (1985), El hombre unidimensional, Artemisa, México.

Marín, Gustavo (2010), Turismo, globalización y mercantilización del espacio y la cultura en la Riviera Maya: un acercamiento a tres escenarios, CIESAS, México.

Martínez Ross, Jesús, y Tania, Camal (2009), El Constituyente de 1974: Antecedentes y debates para la creación de un orden estatal. Gobierno del Estado de Quintana Roo, México. 
Molina, Mario (1998), La globalización económica a debate. Documentos de trabajo, Instituto Complutense de Estudios Internacionales, Madrid.

Robert, A. (NOMBRES) y Messias da Costa, W. (2009), Geografía crítica. La valorización del espacio, Itaca, México.

Sabatini, F.; Cáceres, G. y Cerda, J. (2001), “Segregación residencial en las principales ciudades chilenas: Tendencias de las tres últimas décadas y posibles cursos de acción”, en EURE, núm. 82, LUGAR

Secretaría de Planeación y Desarrollo Regional del Estado de Quintana Roo (SEPLADER) (2008), Actualización del Programa de Desarrollo Urbano del Centro de Población de Puerto Morelos, Municipio de Benito Juárez, Quintana Roo, México.

SINTRA (2011), A punto de concluir obras de infraestructura turística en Puerto Morelos y Bacalar: SINTRA en :http://institutoforestal.qroo.gob.mx/ portal/WebPage.php?Pagina=NotaVoc.php\&IdNota=4769 ( consultado 28 de diciembre de 2011).

Yory, C., (2006), Ciudad, consumo y globalización, Editorial Pontificia Universidad Javeriana, Bogotá.

Zizumbo, Lilia (1998), Turismo y vida cotidiana, Universidad Autónoma del Estado de México, México.

Reglamentos

Municipio de Benito Juárez (1995), Reglamento de anuncios para el municipio de Benito Juárez, Quintana Roo, México.

Municipio de Benito Juárez (2008), Reglamento para el comercio en vía pública del municipio de Benito Juárez, Quintana Roo, México.

Municipio de Benito Juárez (2008), Reglamento de construcción para el municipio de Benito Juárez, Quintana Roo, México.

Municipio de Benito Juárez (1997), Reglamento de mercados y centros comerciales del municipio de Benito Juárez, Quintana Roo, México.

Municipio de Benito Juárez (1990), Reglamento de Espectáculos y Diversiones para el municipio de Benito Juárez, Quintana Roo, México.

Recibido: 30.03.2012

Aceptado: 09.01.2013 